REVIEW

\title{
Hypopituitarism following traumatic brain injury: prevalence is affected by the use of different dynamic tests and different normal values
}

Nieke E Kokshoorn, Moniek J E Wassenaar, Nienke R Biermasz, Ferdinand Roelfsema, Johannes W A Smit, Johannes A Romijn and Alberto M Pereira

Department of Endocrinology and Metabolic Diseases C4-R, Leiden University Medical Center, PO Box 9600, 2300 RC Leiden, The Netherlands

(Correspondence should be addressed to N E Kokshoorn; Email: n.e.kokshoorn@lumc.nl)

\begin{abstract}
Objective: Traumatic brain injury (TBI) has emerged as an important cause of hypopituitarism. However, considerable variations in the prevalence of hypopituitarism are reported. These can partly be explained by severity of trauma and timing of hormonal evaluation, but may also be dependent on endocrine tests and criteria used for diagnosis of hypopituitarism.

Methods: Systematic review of studies reporting prevalence of hypopituitarism in adults $\geq 1$ year after TBI focusing on used (dynamic) tests and biochemical criteria.

Results: We included data from 14 studies with a total of 931 patients. There was considerable variation in definition of hypopituitarism. Overall, reported prevalences of severe $\mathrm{GH}$ deficiency varied between 2 and 39\%. Prevalences were 8-20\% using the GHRH-arginine test (cutoff $<9 \mu \mathrm{g} / \mathrm{l}$ ), $11-39 \%$ using the glucagon test (cutoff $1-5 \mu \mathrm{g} / \mathrm{l}$ ), $2 \%$ using the GHRH test (no cutoff), and 15-18\% using the insulin tolerance test (ITT; cutoff $<3 \mu \mathrm{g} / \mathrm{l}$ ).

Overall, the reported prevalence of secondary adrenal insufficiency had a broad range from 0 to $60 \%$. This prevalence was $0-60 \%$ with basal cortisol (cutoff $<220$ or $<440 \mathrm{nmol} / \mathrm{l}$ ), $7-19 \%$ using the ACTH test, and $5 \%$ with the ITT as first test (cutoff $<500$ or $<550 \mathrm{nmol} / \mathrm{l}$ ). Secondary hypothyroidism was present in $0-19 \%$ (free thyroxine) or 5-15\% (thyroid-releasing hormone stimulation). Secondary hypogonadism was present in 0-29\%.

Conclusion: The reported variations in the prevalence rates of hypopituitarism after TBI are in part caused by differences in definitions, endocrine assessments of hypopituitarism, and confounding factors. These methodological issues prohibit simple generalizations of results of original studies on TBI-associated hypopituitarism in the perspective of meta-analyses or reviews.
\end{abstract}

European Journal of Endocrinology 162 11-18

\section{Introduction}

In recent years, an increasing number of studies have reported the presence of pituitary insufficiency in patients who experienced traumatic brain injury (TBI) (1-14). The prevalence of pituitary insufficiency after TBI appeared to be unexpectedly high $(15,16)$. Remarkably, the prevalence rates varied considerably among the different studies, ranging from 15 to even $90 \%$ of the patients.

Several factors influence the prevalence of hypopituitarism after TBI. First, the time interval between TBI and the assessment of pituitary function, since hormone alterations mimicking pituitary insufficiency are prevalent in the early post-traumatic period. Secondly, the type and severity of the brain injury affect the prevalence of hypopituitarism, because persistent pituitary insufficiency is only frequent after severe TBI $(7,15)$. Thirdly, endocrine tests, assays, and criteria for the diagnosis of hypopituitarism differ between the studies. Although many reviews have addressed TBI-related hypopituitarism, a detailed comparison of these methodological issues between the different studies has not been performed for each pituitary axis.

We hypothesized that these methodological differences may have contributed, at least in part, to the discrepancies in prevalence rates of hypopituitarism after TBI, reported by the different studies. Therefore, the aim of this study was to critically compare the pituitary function tests, and definitions of hypopituitarism between studies that assessed the longterm outcome of TBI on pituitary function. 


\section{Subjects and methods}

\section{Search strategy}

We performed a search in PubMed, EMBASE, Web of Science, and the Cochrane database for all published studies on the association between TBI and hypopituitarism. The following search strategy was used: (TBI OR traumatic brain injuries) AND (traumatic OR trauma) AND (hypopituitarism OR hypopituitar* OR hypothalamus-hypophysis system OR 'hypothalamopituitary dysfunction' OR 'pituitary dysfunction' OR hypothalamo-hypophyseal system OR pituitary gland OR hypophysis).

In addition, the references of relevant articles were checked for additional articles. The search was performed on 23 March 2009. Only original articles were included. We used the following exclusion criteria: pediatric or adolescent population; publications concerning pituitary testing $<12$ months after injury (a median of 12 months was accepted); articles that evaluated pituitary insufficiency after subarachnoidal bleeding.

\section{Data review}

The following data were extracted from each study: i) age and gender, ii) the endocrine tests used for assessment of each pituitary axis, iii) definitions used for pituitary insufficiency for each pituitary axis, iv) hormone assays, v) reference values provided in the manuscript, and vi) use of control populations. Tables were constructed per pituitary axis. These tables are added as supplemental data files. The GH-insulin-like growth factor 1 (IGF1) axis is presented in Supplementary Table 1 (see section on supplementary data given at the end of this article) the pituitary-adrenal axis in Supplementary Table 2, the pituitary-thyroidal axis in Supplementary Table 3, the pituitary-gonadal axis in Supplementary Table 4, and prolactin (PRL) in Supplementary Table 5.

\section{Results}

We identified 278 articles, of which 218 were excluded on the basis of title and abstract. Of the remaining 60 articles, 46 were reviews. Finally, 14 original studies were included with a total of 931 patients. Details of these studies are summarized in Table 1. The number of patients evaluated by the different studies varied between 22 and 105.

\section{The GH-IGF1 axis}

The prevalence of GH deficiency (GHD) ranged between 2 and 66\% (severe GHD 39\%; Figs 1 and 2 and Supplementary Table 1). The presence of GHD was associated with higher body mass index (BMI) values in some of the studies (see Fig. 1). In addition to basal

Table 1 Studies on TBI and pituitary deficiency.

\begin{tabular}{|c|c|c|c|c|c|c|}
\hline Study & $\begin{array}{c}\text { Year of } \\
\text { publication }\end{array}$ & $\begin{array}{l}\text { Number of } \\
\text { patients }\end{array}$ & $\begin{array}{l}\text { Time of testing } \\
\text { post TBI } \\
\text { (months (median)) }\end{array}$ & $\begin{array}{l}\text { Trauma severity } \\
\text { (GCS) }\end{array}$ & $\begin{array}{l}\text { BMI } \\
\left(\mathrm{kg} / \mathrm{m}^{2}\right)\end{array}$ & $\begin{array}{c}\text { Any pituitary } \\
\text { deficiency } \\
(\%)\end{array}$ \\
\hline Kelly et al. (6) & 2000 & 22 & 3-276 (median 26) & $3-15$ & $25.1 \pm 6.5$ & 37 \\
\hline Lieberman et al. (9) & 2001 & 70 & 1-276 (median 13) & $\begin{array}{l}3-15 \\
84 \% \text { GCS } \leq 8\end{array}$ & $N R$ & 69 \\
\hline Bondanelli et al. (3) & 2004 & 50 & $12-64$ & $\begin{array}{l}3-15 \\
54 \% \text { GCS } \leq 8\end{array}$ & $24.6 \pm 0.4$ & 54 \\
\hline Agha et al. (1) & 2004 & 102 & 6-36 (median 17) & $\begin{array}{l}3-13 \\
56 \% \text { GCS } \leq 8\end{array}$ & NR & 28 \\
\hline Popovic et al. (10) & 2004 & 67 & $12-264$ & $3-13$ & $24.8 \pm 0.5$ & 34 \\
\hline Aimaretti et al. (2) & 2005 & 70 & 12 & $\begin{array}{l}3-15 \\
21 \% \text { GCS } \leq 8\end{array}$ & $23.8 \pm 0.4$ & 23 \\
\hline Leal-Cerro et al. (8) & 2005 & 99 & $>12$ & $\leq 8$ & $\begin{array}{r}25.2 \pm 3.0 \\
(n=44)\end{array}$ & 25 \\
\hline Schneider et al. (11) & 2006 & 70 & 12 & $3-15$ & $23.8 \pm 3.2$ & 36 \\
\hline Tanriverdi et al. (12) & 2006 & 52 & 12 & $\begin{array}{l}3-15 \\
25 \% \text { GCS } \leq 8\end{array}$ & NR & 51 \\
\hline Herrmann et al. (5) & 2006 & 76 & $5-47$ & $\leq 8$ & $25.8 \pm 4.2$ & 24 \\
\hline Bushnik et al. (4) & 2007 & 64 & $>12$ months & NR & $\mathrm{NR}$ & 90 \\
\hline Klose et al. (7) & 2007 & 104 & 10-27 (median 13) & $\begin{array}{l}3-15 \\
38 \% \text { GCS } \leq 8\end{array}$ & $25^{a}(17-39)$ & 15 \\
\hline Tanriverdi et al. (14) & 2008 & 30 & 36 & $\begin{array}{l}3-15 \\
16.7 \% \text { GCS } \leq 8\end{array}$ & NR & 30 \\
\hline Wachter et al. (13) & 2009 & 55 & NR & $\begin{array}{l}3-15 \\
17 \% \text { GCS } \leq 8\end{array}$ & NR & 25 \\
\hline Total no. of patients & & 931 & & & & \\
\hline
\end{tabular}

BMI, body mass index reported as mean \pm S.E.M.; GCS, Glasgow Coma Scale score; TBI, traumatic brain injury; NR, not reported.

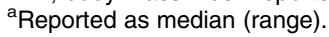




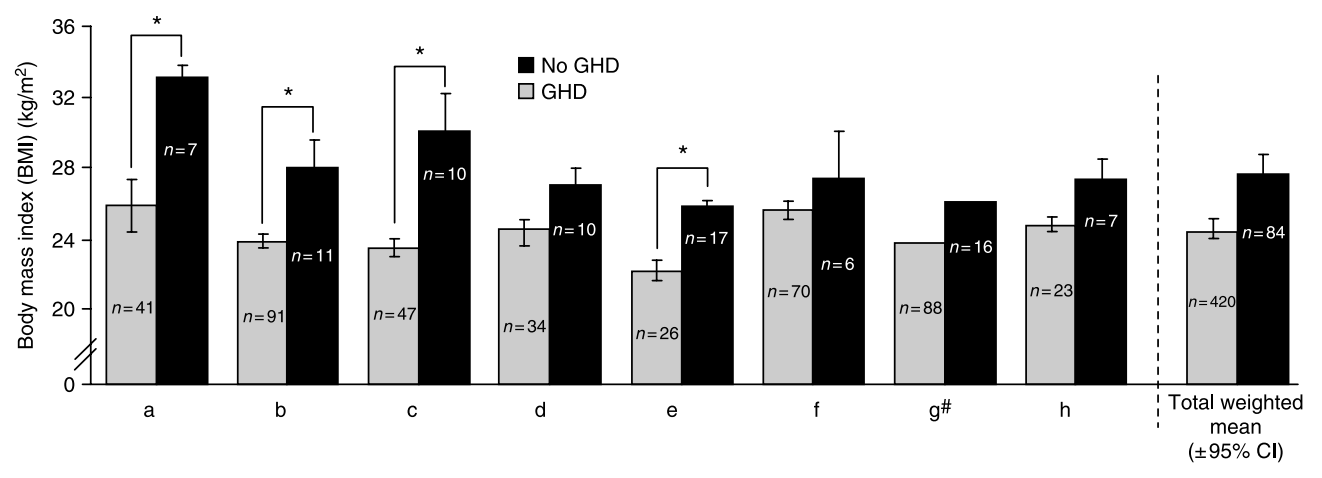

Figure 1 Body mass index in patients diagnosed with versus those without GH deficiency (data available only in 8 out of the 16 studies). a, Lieberman et al. (9); b, Agha et al. (1); c, Popovic et al. (10); d, Leal-Cerro et al. (8); e, Tanriverdi et al. (12); f, Herrmann et al. (5); g, Klose et al. (7); h, Tanriverdi et al. (14); i, weighted total mean (mean $\pm 95 \%$ Cl: no GHD 24.5 (24.2-24.9) versus GHD $27.7(26.7-28.8) \mathrm{kg} / \mathrm{m}^{2}$ ). GHD, GH deficiency; BMI, body mass index; ${ }^{*} P<0.05$. "Data reported as median with range; not included in the total weighted mean.

serum GH and IGF1 values, all studies used a dynamic test to assess GH-secretory reserve. However, different dynamic tests were used.

Three studies $(196 / 931=21 \%$ of all patients $)$ used the combined GHRH-arginine test as the first screening. The criterion for severe GHD was a peak GH level $<9.0 \mu \mathrm{g} / \mathrm{l}$ in all three, which was not adjusted for BMI. Prevalence rates of severe GHD varied between 8 and $20 \%$ (weighted mean 12\%) (2, 3, 5). Schneider et al. (11) also used the GHRH-arginine test, but only in a subset of the patients (those with abnormal serum cortisol levels, $n=32$ ); the prevalence of GHD in this study was $10 \%$.

Two studies $(112 / 931=12 \%$ of all patients $)$ used an insulin tolerance test (ITT) as the primary screening test $(6,7)$. The criterion for severe GHD was a peak $\mathrm{GH}$ response $<3 \mu \mathrm{g} / \mathrm{l}$ in both, and the prevalence of GHD was comparable (18 and $15 \%$ respectively; weighted mean 16\%).

Of the eight remaining studies, three used a stimulation test with glucagon $(n=209)(1,4,9)$ with prevalence rates for severe GHD between 11 and 39\% (weighted mean 20\%). The cut-off values differed considerably and varied between 1 and $5 \mu \mathrm{g} / \mathrm{l}$ between these studies. Just one study used a stimulation test with GHRH only (number of patients not recorded) reporting a GHD prevalence of $2 \%(13)$. Two studies $(n=119)$ used the combined GHRH + GHRP-6 test with a prevalence of 15 and 33\% respectively (weighted mean $21 \%)(10,12)$. The cut-off values were similar $(\mathrm{GH}<10 \mu \mathrm{g} / \mathrm{l})$ within these studies, and were derived from another report (17).

Finally, two studies used a combination of these tests $(8,14)$. For instance, Agha et al. (1) used a glucagon stimulation test for the initial screening in 102 subjects, and in case of incomplete GH response, they used an ITT $(n=14)$ or combined GHRH+ arginine test $(n=4)$ to confirm GHD.

\section{The pituitary-adrenal axis}

The prevalence of secondary adrenal insufficiency deficiency ranged from 0 to $60 \%$ between the studies (Fig. 3 and Supplementary Table 2).

Four studies $(251 / 931=27 \%$ of all patients $)$ only measured basal morning fasting serum cortisol and/or ACTH levels $(2-4,10)$, resulting in prevalence rates between 0 and $60 \%$ (weighted mean 15\%). The criteria for pituitary-adrenal insufficiency differed between three studies (cortisol <220-440 nmol/l), and were not reported in the fourth study (10). The study reporting the highest prevalence of $60 \%$ used a cut-off value of $440 \mathrm{nmol} / \mathrm{l}(4)$.

Four studies $(145 / 931=12 \%$ of all patients $)$ used an ACTH stimulation test (synacthen; either with 1 or $250 \mu \mathrm{g})$. However, only one study performed this test in all patients and the prevalence of ACTH deficiency was $7 \%$ (9). In the other three studies, only a subset of the patients (those with subnormal basal cortisol levels) underwent stimulation with ACTH. The prevalence in these studies varied between 7 and 19\% (weighted mean $10 \%)(11,12,14)$.

One study $(55 / 931=6 \%$ of all patients $)$ used nonstimulated cortisol values between 1600 and $2000 \mathrm{~h}$ (reference values 63-339 $\mathrm{nmol} / \mathrm{l}$ ), which was followed by a corticotrope-releasing hormone ( $\mathrm{CRH})$ test only in those with values below this reference range, or in those who responded confirmatory to a specific questionnaire (13).

In the remaining five studies $(403 / 931=43 \%$ of all patients), the ITT was used in 169 patients as a primary test $(n=112)$ resulting in a prevalence of $5 \%$ in both studies $(6,7)$, or as a confirmation test in a subset of the patients. Two studies measured basal serum cortisol levels and used ITT as a confirmation test (prevalence of 3 and 11\% respectively) $(5,8)$. One study assessed primarily with a glucagon stimulation test $(n=102)$, and used the ITT and ACTH tests to confirm 

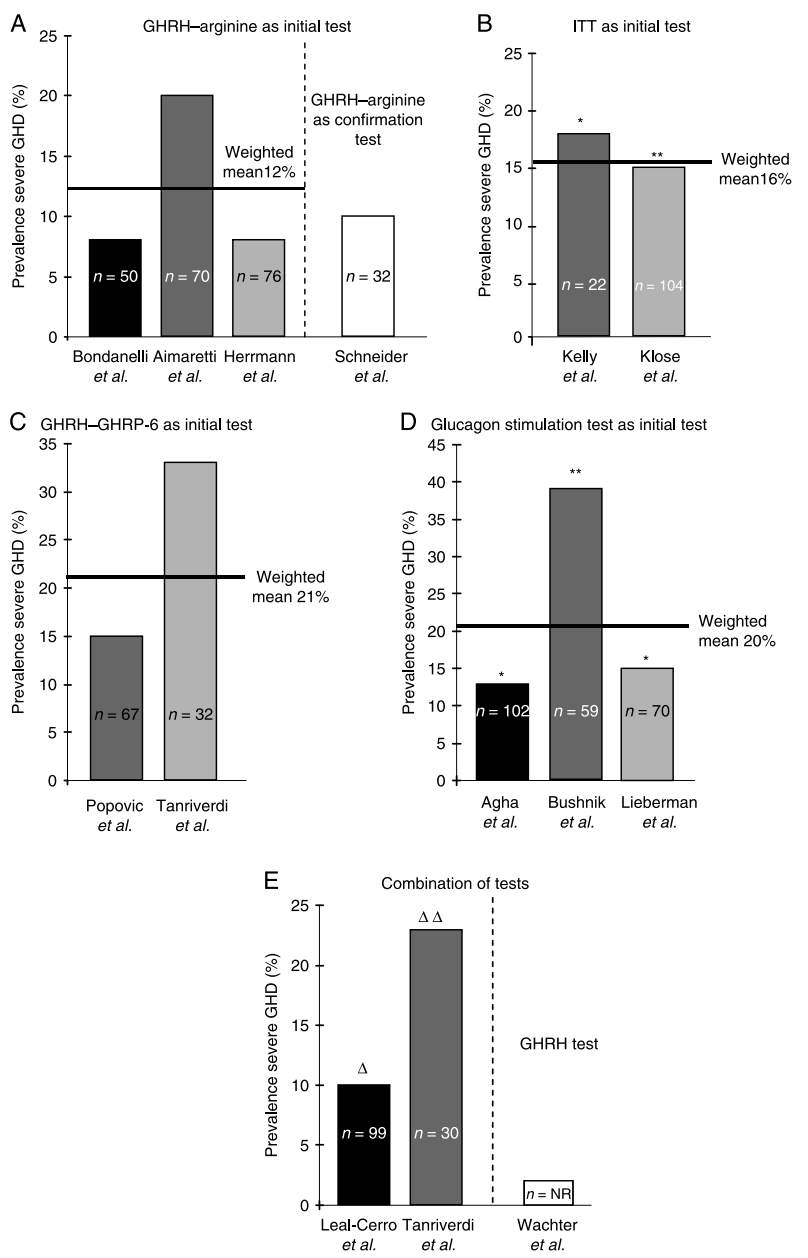

Figure 2 Absolute and weighted mean prevalence rates of severe $\mathrm{GH}$ deficiency (GHD) according to the stimulation tests used per study. The number of patients tested is depicted in each bar. Panel A, the combined GHRH-arginine test; definition severe GHD: peak $\mathrm{GH}<9 \mu \mathrm{g} / \mathrm{l}$ for all four studies. Panel $\mathrm{B}$, the insulin tolerance test (ITT); *definition severe GHD: $\mathrm{GH}<95 \% \mathrm{CL}$ according to AUC; ${ }^{* *}$ definition severe GHD: peak $\mathrm{GH}<3 \mu \mathrm{g} / \mathrm{l}$. Panel C, the combined GHRH-GHRP-6 test; definition severe GHD: peak $\mathrm{GH}<10 \mu \mathrm{g} / \mathrm{l}$ for both studies. Panel $\mathrm{D}$, the glucagon stimulation test; definition severe GHD: " peak GH $<3 \mu \mathrm{g} / \mathrm{l}$; ${ }^{* *}$ peak $\mathrm{GH}<5 \mu \mathrm{g} / \mathrm{l}$. Panel $\mathrm{E}$, combined stimulation tests as initial screening followed by confirmation test; ${ }^{\Delta} \mathrm{GHRH}+\mathrm{GHRP}-6$ test as initial test; ITT and glucagon stimulation test as confirmation tests; ${ }^{\Delta \Delta}$ GHRH + GHRP-6 test as initial test; glucagon stimulation test as confirmation test.

ACTH deficiency (prevalence 13\%) (1). The criteria for a normal cortisol response to hypoglycemia were a peak cortisol level $>550 \mathrm{nmol} / \mathrm{l}$ in one (8), and $>500 \mathrm{nmol} / \mathrm{l}$ in three other studies $(1,5,7)$. The fifth study used a control group of 18 healthy subjects to define normal cortisol responses to ITT (cortisol response $<95 \%$ confidence limit according to the obtained area under the curve) (6). The CRH test was used in only one study and did not report the number of patients (13).

\section{The hypothalamus-pituitary-thyroid axis}

The prevalence of hypothalamus-pituitary-thyroid axis deficiency ranged from 0 to $19 \%$ between the studies (Supplementary Table 3).

The criteria for TSH deficiency were different (see Supplementary Table 3). Nine studies used basal free thyroxine $\left(\mathrm{FT}_{4}\right)$ and $\mathrm{TSH}$ levels only. Within these studies, the cut-off value for decreased $\mathrm{FT}_{4}$ varied between 8 and $12 \mathrm{pmol} / \mathrm{l}(2,5,7,11,14$, $18,19)$. In two studies, reference values were not reported $(4,10)$, one of which (Bushnik et al.) reported the highest prevalence of secondary hypothyroidism.

The thyroid-releasing hormone (TRH) stimulation test was used in five studies, using i.v. doses of 200 (13) and $500 \mu \mathrm{g}(5,6,8,9)$. The criterion for a normal response differed considerably: a TSH peak response $>7 \mathrm{mIU} / \mathrm{l}$, a TSH peak between 5 and $30 \mathrm{mIU} / \mathrm{l}$, or were not reported $(12,13)$.

The prevalence rates between the studies that only measured basal $\mathrm{FT}_{4}$ levels varied between 0 and $19 \%$ (weighted mean 5\%) $(1-5,7,10,11,14)$, and between 5 and $15 \%$ (weighted mean $8 \%$ ) in those that also used TRH $(6,8,9,12,13)$.

A

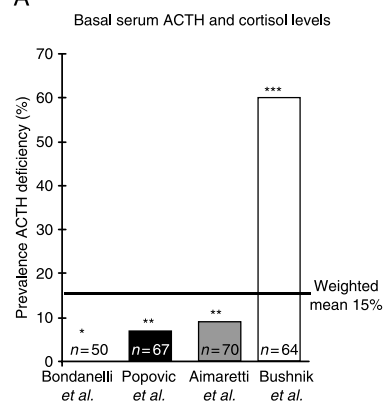

B ACTH test ACTH test in subset of
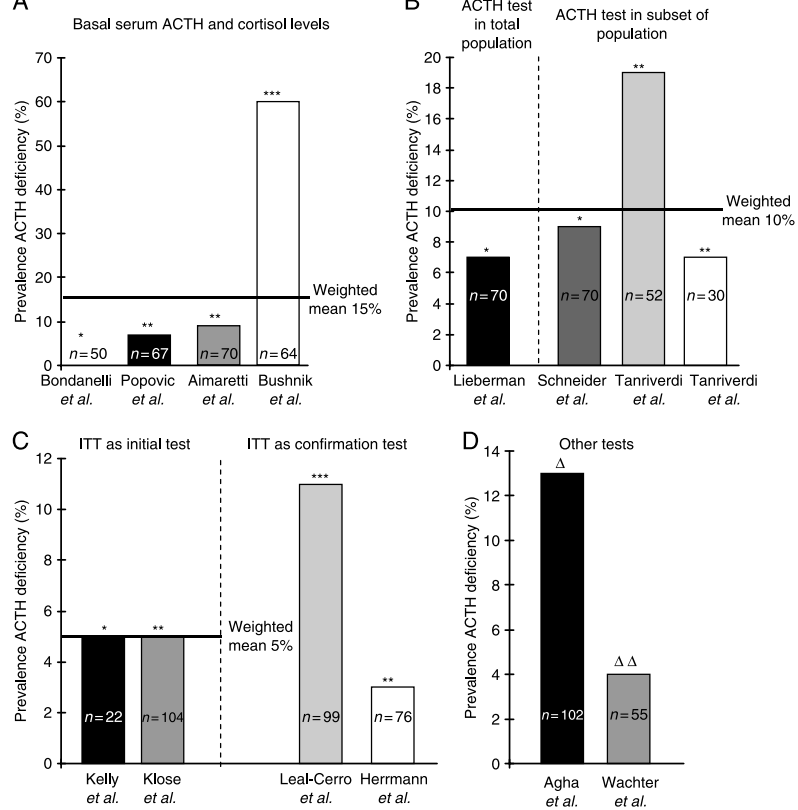

Figure 3 Absolute and weighted mean prevalence rates of corticotropin (HPA axis) deficiency according to the stimulation test used per study. The number of patients tested is depicted in each bar. Panel $A$, basal cortisol concentrations only using different cutoff levels; *cut-off level: NR; ${ }^{* *}$ cut-off level: cortisol $<220 \mathrm{nmol} / /$; ${ }^{* * *}$ cut-off level: cortisol $<440 \mathrm{nmol} / \mathrm{l}$. Panel B, the ACTH stimulation test *using $250 \mu \mathrm{g} \mathrm{ACTH}$ and peak cortisol $<500 \mathrm{nmol} / \mathrm{l}$; **using $1 \mu \mathrm{g} \mathrm{ACTH}$ and peak cortisol $<550 \mathrm{nmol} / \mathrm{l}$. Panel C, the insulin tolerance test (ITT); " peak cortisol $<95 \% \mathrm{CL}$ according to AUC; ${ }^{\star *}$ peak cortisol $<500 \mathrm{nmol} / /$; ${ }^{* \star *}$ peak cortisol $<550 \mathrm{nmol} / \mathrm{l}$. Panel $D$, other stimulation tests: ${ }^{\Delta}$ the glucagon stimulation test; ${ }^{\Delta \Delta} \mathrm{CRH}$ test. $\mathrm{NR}$, not reported. 


\section{The hypothalamus-pituitary-gonadal axis}

The hypothalamus-pituitary-gonadal axis deficiency ranged from 0 to $29 \%$ (weighted mean 13\%) between the studies (Supplementary Table 4). Basal LH and FSH were measured in all but one study (4). Basal estradiol ( $\mathrm{E}_{2}$; in women) was measured in 9 studies, and the menstrual history was recorded in 10 out of 14 studies. Testosterone (in men) was measured in all studies. In four studies, a GnRH stimulation test was performed in a subset of the patients $(6,8,9,13)$. The criterion for a normal test response differed between the studies (see Supplementary Table 4). The definition of secondary hypogonadism was mainly based on basal testosterone (in men) and $\mathrm{E}_{2}$ concentrations (in women) below the reference ranges, in the presence of decreased or normal LH and FSH levels. A subset of the studies also incorporated the GnRH test result (see above) and menstrual cycle abnormalities in premenopausal females.

\section{Prolactin}

The prevalence of abnormal serum PRL concentrations ranged from 0 to $16 \%$ (Supplementary Table 5). Abnormal PRL secretion was defined as hyperprolactinemia $(8 / 14$ studies) $(1,2,5,7,9,11,12,14)$, hypoprolactinemia (1 study) (6), or both (3). In accordance, prevalence rates were between 3 and $12 \%$ using the definition of hyperprolactinemia, $0 \%$ using the definition of hypoprolactinemia, and $16 \%$ using the combination of both. Out of the 14 studies, 10 measured basal serum PRL concentrations only (1-3, 5, 7, 9-12, 14). Three studies also used a TRH test (doses 100 and $500 \mu \mathrm{g}$ respectively) $(6,8,13)$. Prevalence rates were not reported in two of these $(8,13)$ and were $0 \%$ in the third (6).

\section{Discussion}

This review demonstrates that the endocrine evaluations and definitions of hypopituitarism differ considerably among the studies that have assessed TBI-related hypopituitarism. From the existing literature, the notion emerges that most of the tests that are currently used to establish the diagnosis of hypopituitarism in general, and GHD in specific, are not validated sufficiently regarding cut-off values, reproducibility, and dependence on confounding factors in TBI patients. In general, there are hardly any data on reproducibility of tests or dependence on confounding factors in TBI patients. One factor that comes forward in the current review is the potential effect of increased BMI, which in general is associated with decreased $\mathrm{GH}$ responses to $\mathrm{GH}$ stimulation tests. Therefore, increased BMI may result in an inadvertently higher incidence rate of GHD, if the cut-off values for normal $\mathrm{GH}$ responses to $\mathrm{GH}$ stimulation tests are not adapted according to BMI. All these methodological issues limit the applicability of the individual studies, i.e. the decision whether the study results are valid for patients to whom the results are generalizable but who are subjected to a different endocrine diagnostic assessment than the original study population. Moreover, these methodological limitations prohibit simple generalizations of the results from the perspective of a meta-analysis or a review.

The question arises whether post-traumatic hypopituitarism, especially GHD, has been over-diagnosed on the basis of the older cross-sectional studies. Consensus guidelines for the evaluation of adult GHD state that different dynamic tests can be used to diagnose GHD, including the ITT, the glucagon stimulation test, the combined GHRH-arginine test, and the combined GHRH-GHRP-6 test (20). The present assessment, however, documents a higher prevalence of GHD for the glucagon stimulation test and the combined GHRHGHRP- 6 test, compared to the results of the combined GHRH-arginine test and the ITT. With the exception of the ITT (which was used in only $12 \%$ of the patients $(6$, $7)$ ), the outcome of each test varied greatly (see Fig. 2) using different (glucagon stimulation test) or similar cut-off levels (other test). In addition, the studies that used two dynamic tests to assess $\mathrm{GH}$ reserve revealed a lower prevalence of GHD than the studies with only one test. Moreover, the results of $\mathrm{GH}$ stimulation tests are confounded by BMI, with higher BMI being associated with decreased GH responses. Although BMI-adjusted reference values have been reported (21), none of the studies on TBI-associated GHD reports adjusted their cut-off values for BMI. Moreover, the data indicate that BMI tends to be higher in the TBI patients with GHD (see Fig. 1). Finally, an important aspect is that most patients had only GHD or one additional pituitary hormone deficiency. Therefore, one test may not be sufficiently reliable and the use of two tests would increase the confidence in the diagnosis, although only if the two tests yield concordant results. However, the application of two tests may introduce an even greater uncertainty in case of discordant results. This discrepancy has been documented for instance in GHD in irradiated patients, in whom the attenuation in GH responses to the ITT was greater compared with the combined GHRHarginine test (22). These factors impose major problems for an accurate assessment of GHD in these patients. Therefore, these methodological issues have contributed to the suspicion that GHD is probably over diagnosed in the older cross-sectional studies.

We observed similar variations in test results of the pituitary-adrenal axis (see Fig. 3). The use of different tests with different cut-off values resulted in prevalence rates that varied between 5 and 19\%. ACTH deficiency can be diagnosed by measuring basal early morning cortisol levels: values below $100 \mathrm{nmol} / \mathrm{l}$ are indicative of ACTH deficiency, whereas cortisol values above $500 \mathrm{nmol} / \mathrm{l}$ essentially exclude ACTH deficiency. 
The ACTH stimulation test is reliable in diagnosing clinically significant adrenal insufficiency in patients who are at risk (23-25). ACTH stimulation tests, however, are not fully reliable in excluding the presence of mild secondary adrenal insufficiency (26). The ITT still remains the golden standard, and has the advantage that $\mathrm{ACTH} /$ cortisol and GH secretory reserve can be assessed simultaneously. If an ITT is contraindicated, a CRH test can be alternatively used (27). The effect of the initial choice for a specific stimulation test on the variation in outcome of adrenal insufficiency and GHD based on the available data after TBI is illustrated in Fig. 4.

The diagnosis of secondary hypothyroidism is usually made based on $\mathrm{FT}_{4}$ values. However, basal $\mathrm{FT}_{4}$ levels show a relatively small intra-individual variability, although inter-individual variability is large (28). As a consequence, a diagnosis of possible secondary hypothyroidism may not be straightforward, since $\mathrm{FT}_{4}$ levels within the normal reference range can reflect hypothyroidism in one patient but euthyroidism in another patient. Basal TSH levels are also of limited help for the diagnosis of secondary hypothyrodism, since normal or even increased levels of TSH can be found (29). In addition, a TRH test is of limited value because patients with central hypothyroidism may show different patterns of TSH responses to TRH, with absent or exaggerated responses, which considerably overlap with those found in healthy volunteers. Moreover, the magnitude of the TSH peak is proportional to the injected TRH dose, is higher in women, and tends to decline with age (30). In accordance, the prevalence rates were not affected by the use of TRH stimulation. In analogy, the interpretation of the GnRH test is complex, and individual responses vary greatly in both adults and children (31). In men, it is sufficient to measure non-stimulated LH, FSH, and testosterone concentrations. In premenopausal women, the evaluation of the menstrual cycle is a prerequisite, whereas in postmenopausal women, the absence of increased LH and FSH levels almost invariably indicates hypogonadotropic hypogonadism.

Analytical factors will most likely also have affected the different outcomes of the studies. For instance, the $\mathrm{GH}$ and cortisol assays varied between studies, and it is known that the between-laboratory performance of the $\mathrm{GH}$ assay is not very good. Moreover, most were not validated sufficiently regarding normal cut-off values, reproducibility, and dependence on confounding factors even in a 'normal' population. None of these tests have been validated in TBI patients at all.

The time point of evaluation may also influence outcome; therefore, we focused only on studies in the chronic phase after TBI, i.e. 1 year after the trauma. Studies that analyzed patients with a median duration of 12 months after TBI, however, were also included. Thus, part of these patients was assessed within 12 months after TBI. In general, the transient effects of TBI mimicking pituitary insufficiency are almost exclusively reported only within the first 6 months after TBI (15). Therefore, it is unlikely that the pituitary results of the studies with a median duration of followup of 12 months of TBI are caused by the transient effects of TBI. This is supported by similar results of additional analyses of the remaining studies, which included only patients with a followup of more than 12 months after TBI. Lastly, the underlying mechanisms of TBI-related hypopituitarism have not been resolved. It is unclear to what extent hypothalamic versus pituitary damage is present in TBI patients with hypopituitarism and what impact these processes may have on endocrine tests.

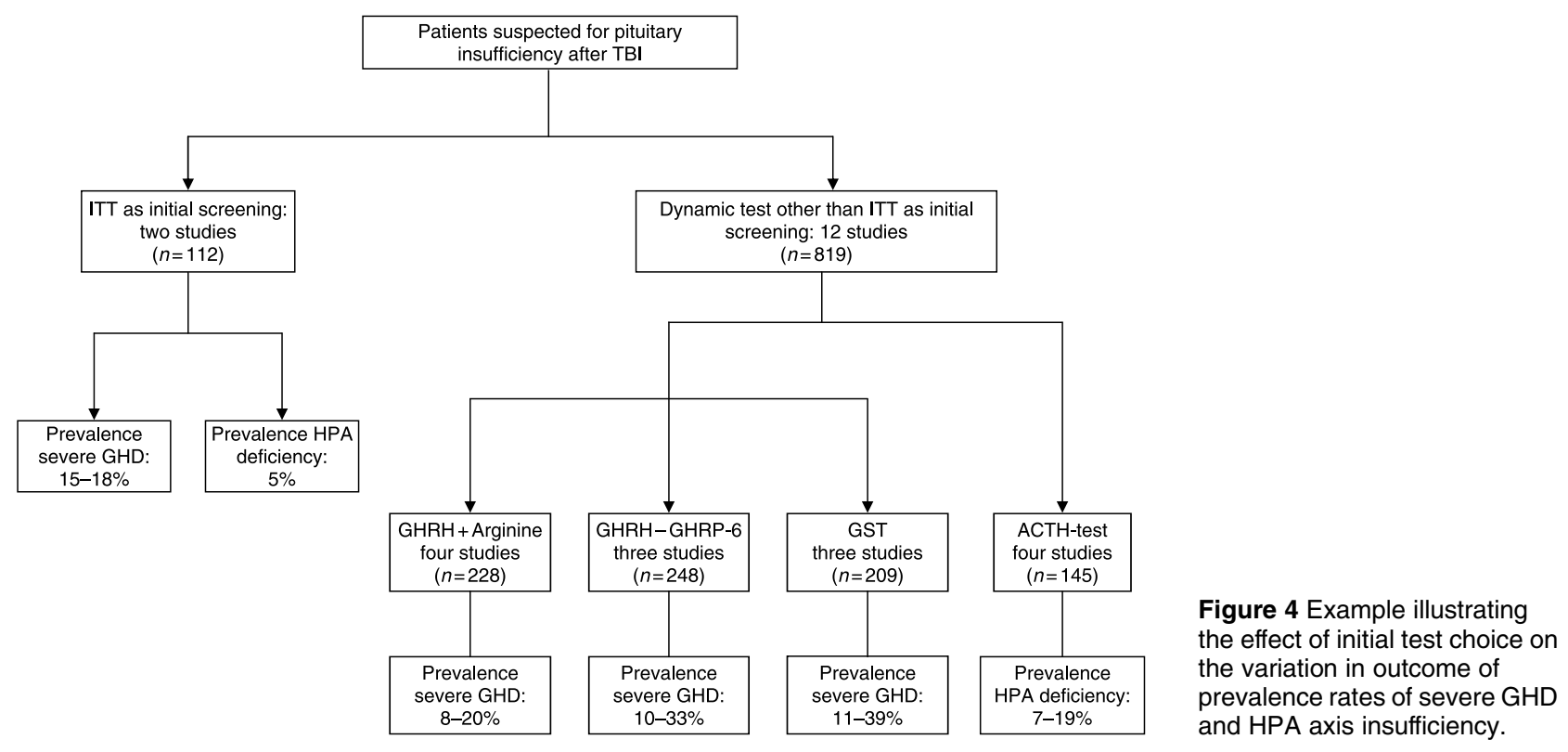

www.eje-online.org 
Recently, many clinical reviews have summarized the studies on pituitary insufficiency after TBI $(15,16)$. These studies concluded that hypopituitarism is a common complication of TBI and might contribute to morbidity and poor recovery after brain injury (16). However, these reviews did not take into account the variability in diagnostic strategies and definitions of pituitary insufficiency. These discrepancies, in addition to differences in inclusion and exclusion criteria, limit the possibility to compare the results of studies on TBI. We agree with Klose \& Feldt-Rasmussen that future studies should be designed to ensure a high diagnostic robustness for proper identification of reliable predictors, as the results may be highly dependent on diagnostic pitfalls (15).

In conclusion, the reported prevalence rates of pituitary insufficiency after TBI vary considerably, which is associated with major differences in endocrine and analytical methods of assessment and definitions used for hypopituitarism. This does not only apply to the case of TBI-related hypopituitarism, but most likely also to hypopituitarism caused by pituitary diseases. The same caution with respect to the evaluation of pituitary function should be considered in pituitary diseases, because the diagnosis of definitive hypopituitarism remains a challenge in clinical endocrinology. In pituitary pathology, definitive data on robust accuracy of basal or dynamic hormonal tests are incomplete.

\section{Supplementary data}

This is linked to the online version of the paper at http://dx.doi.org/ 10.1530/EJE-09-0601.

\section{Declaration of interest}

The authors declare that there is no conflict of interest that could be perceived as prejudicing the impartiality of the research reported.

\section{Funding}

This research did not receive any specific grant from any funding agency in the public, commercial, or not-for-profit sector.

\section{References}

1 Agha A, Rogers B, Sherlock M, O’Kelly P, Tormey W, Phillips J \& Thompson CJ. Anterior pituitary dysfunction in survivors of traumatic brain injury. Journal of Clinical Endocrinology and Metabolism $2004894929-4936$.

2 Aimaretti G, Ambrosio MR, Di Somma C, Gasperi M, Cannavo S, Scaroni C, Fusco A, Del Monte P, De Menis E, Faustini-Fustini M, Grimaldi F, Logoluso F, Razzore P, Rovere S, Benvenga S, Degli Uberti EC, De Marinis L, Lombardi G, Mantero F, Martino E, Giordano G \& Ghigo E. Residual pituitary function after brain injuryinduced hypopituitarism: a prospective 12-month study. Journal of Clinical Endocrinology and Metabolism 200590 6085-6092.

3 Bondanelli M, De Marinis L, Ambrosio MR, Monesi M, Valle D, Zatelli MC, Fusco A, Bianchi A, Farneti M \& degli Uberti EC. Occurrence of pituitary dysfunction following traumatic brain injury. Journal of Neurotrauma 200421 685-696.
4 Bushnik T, Englander J \& Katznelson L. Fatigue after TBI: association with neuroendocrine abnormalities. Brain Injury 200721 559-566.

5 Herrmann BL, Rehder J, Kahlke S, Wiedemayer H, Doerfler A, Ischebeck W, Laumer R, Forsting M, Stolke D \& Mann K. Hypopituitarism following severe traumatic brain injury. Experimental and Clinical Endocrinology and Diabetes $2006 \mathbf{1 1 4}$ 316-321.

6 Kelly DF, Gonzalo IT, Cohan P, Berman N, Swerdloff R \& Wang C. Hypopituitarism following traumatic brain injury and aneurysmal subarachnoid hemorrhage: a preliminary report. Journal of Neurosurgery 200093 743-752.

7 Klose M, Juul A, Poulsgaard L, Kosteljanetz M, Brennum J \& FeldtRasmussen U. Prevalence and predictive factors of post-traumatic hypopituitarism. Clinical Endocrinology 200767 193-201.

8 Leal-Cerro A, Flores JM, Rincon M, Murillo F, Pujol M, GarciaPesquera F, Dieguez C \& Casanueva FF. Prevalence of hypopituitarism and growth hormone deficiency in adults long-term after severe traumatic brain injury. Clinical Endocrinology 200562 $525-532$.

9 Lieberman SA, Oberoi AL, Gilkison CR, Masel BE \& Urban RJ. Prevalence of neuroendocrine dysfunction in patients recovering from traumatic brain injury. Journal of Clinical Endocrinology and Metabolism 200186 2752-2756.

10 Popovic V, Pekic S, Pavlovic D, Maric N, Jasovic-Gasic M, Djurovic B, Medic-Stojanoska M, Zivkovic V, Stojanovic M, Doknic M, Milic N, Djurovic M, Dieguez C \& Casanueva FF. Hypopituitarism as a consequence of traumatic brain injury (TBI) and its possible relation with cognitive disabilities and mental distress. Journal of Endocrinological Investigation $2004 \mathbf{2 7}$ 1048-1054.

11 Schneider HJ, Schneider M, Saller B, Petersenn S, Uhr M, Husemann B, von Rosen F \& Stalla GK. Prevalence of anterior pituitary insufficiency 3 and 12 months after traumatic brain injury. European Journal of Endocrinology $2006154259-265$.

12 Tanriverdi F, Senyurek H, Unluhizarci K, Selcuklu A, Casanueva FF \& Kelestimur F. High risk of hypopituitarism after traumatic brain injury: a prospective investigation of anterior pituitary function in the acute phase and 12 months after trauma. Journal of Clinical Endocrinology and Metabolism 200691 2105-2111.

13 Wachter D, Gundling K, Oertel MF, Stracke H \& Boker DK. Pituitary insufficiency after traumatic brain injury. Journal of Clinical Neuroscience 200916 202-208.

14 Tanriverdi F, Ulutabanca H, Unluhizarci K, Selcuklu A, Casanueva FF \& Kelestimur F. Three years prospective investigation of anterior pituitary function after traumatic brain injury: a pilot study. Clinical Endocrinology 200868 573-579.

15 Klose M \& Feldt-Rasmussen U. Does the type and severity of brain injury predict hypothalamo-pituitary dysfunction? Does posttraumatic hypopituitarism predict worse outcome? Pituitary $200811255-261$.

16 Schneider HJ, Kreitschmann-Andermahr I, Ghigo E, Stalla GK \& Agha A. Hypothalamopituitary dysfunction following traumatic brain injury and aneurysmal subarachnoid hemorrhage: a systematic review. Journal of the American Medical Association 2007298 1429-1438.

17 Popovic V, Leal A, Micic D, Koppeschaar HP, Torres E, Paramo C, Obradovic S, Dieguez C \& Casanueva FF. GH-releasing hormone and GH-releasing peptide- 6 for diagnostic testing in GH-deficient adults. Lancet 2000356 1137-1142.

18 Agha A, Phillips J \& Thompson CJ. Hypopituitarism following traumatic brain injury (TBI). British Journal of Neurosurgery 2007 $21210-216$.

19 Bondanelli M, Ambrosio MR, Cavazzini L, Bertocchi A, Zatelli MC, Carli A, Valle D, Basaglia N \& Uberti EC. Anterior pituitary function may predict functional and cognitive outcome in patients with traumatic brain injury undergoing rehabilitation. Journal of Neurotrauma 200724 1687-1697.

20 Ghigo E, Aimaretti G \& Corneli G. Diagnosis of adult GH deficiency. Growth Hormone \& IGF Research 200818 1-16. 
21 Corneli G, Di Somma C, Baldelli R, Rovere S, Gasco V, Croce CG, Grottoli S, Maccario M, Colao A, Lombardi G, Ghigo E, Camanni F \& Aimaretti F. The cut-off limits of the GH response to GH-releasing hormone-arginine test related to body mass index. European Journal of Endocrinology 2005153 $257-264$.

22 Darzy KH, Pezzoli SS, Thorner MO \& Shalet SM. Cranial irradiation and growth hormone neurosecretory dysfunction: a critical appraisal. Journal of Clinical Endocrinology and Metabolism $2007921666-1672$.

23 Agha A, Tomlinson JW, Clark PM, Holder G \& Stewart PM. The long-term predictive accuracy of the short synacthen (corticotropin) stimulation test for assessment of the hypothalamic-pituitary-adrenal axis. Journal of Clinical Endocrinology and Metabolism 200691 43-47.

24 Clayton RN. Short Synacthen test versus insulin stress test for assessment of the hypothalamo [correction of hypothalmo]pituitary-adrenal axis: controversy revisited. Clinical Endocrinology 199644 147-149.

25 Stewart PM, Corrie J, Seckl JR, Edwards CR \& Padfield PL. A rational approach for assessing the hypothalamo-pituitaryadrenal axis. Lancet 19881 1208-1210.

26 Giordano R, Picu A, Bonelli L, Balbo M, Berardelli R, Marinazzo E, Corneli G, Ghigo E \& Arvat E. Hypothalamus-pituitary-adrenal axis evaluation in patients with hypothalamo-pituitary disorders: comparison of different provocative tests. Clinical Endocrinology 200868 935-941.

27 Sesmilo G, Halperin I \& Puig-Domingo M. Endocrine evaluation of patients after brain injury: what else is needed to define specific clinical recommendations? Hormones 20076 132-137.

28 Andersen S, Bruun NH, Pedersen KM \& Laurberg P. Biologic variation is important for interpretation of thyroid function tests. Thyroid 200313 1069-1078.

29 Adriaanse R, Romijn JA, Endert E \& Wiersinga WM. The nocturnal thyroid-stimulating hormone surge is absent in overt, present in mild primary and equivocal in central hypothyroidism. Acta Endocrinologica 1992126 206-212.

30 Faglia G. The clinical impact of the thyrotropin-releasing hormone test. Thyroid $1998 \mathbf{8} 903-908$.

31 Westwood ME, Butler GE, McLellan AC \& Barth JH. The combined pituitary function test in children: an evaluation of the clinical usefulness of TRH and LHRH stimulation tests through a retrospective analysis of one hundred and twenty six cases. Clinical Endocrinology 200052 727-733.

Received 24 September 2009

Accepted 25 September 2009 